\title{
A RETERRITORIALIZAÇÃO DOS MIGRANTES NORDESTINOS EM RIO DAS PEDRAS
}

\author{
Luciano Ximenes Aragão*
}

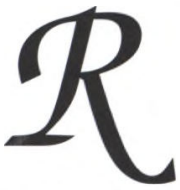

io das Pedras é uma comunidade localizada na Zona Oeste do Rio de Janeiro, na Baixada de Jacarepaguá, situada entre a opulenta Barra da Tijuca, o maciço da Tijuca e o Anil. Na recontagem de 1996, feita pelo IBGE - Instituto Brasileiro de Geografia e Estatística, essa localidade apresentava 7.439 domicílios e 24.581 habitantes. Para a Prefeitura e para o presidente da Associação de Moradores, ultrapassa 65 mil residentes.

Segundo pesquisa realizada pelo Departamento de Sociologia e Política da PUC-Rio, $60 \%$ dos moradores de Rio das Pedras são migrantes. Sugere-se, desse modo, que uma parte significativa dos outros $40 \%$ sejam filhos de migrantes, a segunda geração.

É uma comunidade de formação recente, tendo suas primeiras ocupações iniciadas no final dos anos cinqüenta (do século $\mathrm{XX}$ ), sendo que o período de maior crescimento populacional e expansão territorial ocorreu nos anos 1980 e 1990, revelando as dificuldades do poder público frente à crise habitacional que atinge a cidade. Também indica que o crescimento das comunidades de baixa renda não é alimentado exclusivamente pelos fluxos migratórios, na medida em que houve sua redução nas últimas décadas, para o caso do Rio de Janeiro.

Reconhecida como "uma comunidade de nordestinos", Rio das Pedras apresenta ainda como especificidade o fato de se manter livre da "violência" desencadeada pela territorialização do tráfico de drogas; isto é reiteradamente indicado pelas lideranças locais e pelos seus moradores, além de amplamente divulgado nos meios de comunicação.

Sua ocupação e expansão aparecem atreladas à expansão urbana da cidade do Rio de Janeiro, combinada com o boom imobiliário, especificamente, da Barra da Tijuca e da baixada de Jacarepaguá. Sob a conjuntura econômica criada pelo "milagre" brasileiro, foram estabelecidas as condições sobre as quais aquele setor da economia se dispôs de benefícios, via canalização de investimentos - por meio do ex-BNH - Banco Nacional de Habitação - garantindo a hegemonia de grandes investidores, o que contribuiu para um processo de concentração de capital. Desencadeou-se ou intensificou-se a orientação de fluxos migratórios, alimentados por redes sociais, posto que todos os migrantes entrevistados mencionam que, ao migrar, tiveram apoio de algum parente ou pessoa conhecida. Além disso, pode-se acrescentar as informações, obtidas junto às lideranças comu- nitárias e também dos próprios moradores entrevistados, de que uma parcela significativa dos moradores de Rio das Pedras trabalhava (ou ainda trabalham) na construção civil.

Essas redes sociais articulam o local de origem com o de destino, pois as informações dos que já realizaram o processo migratório potencializa a partida de outros parentes, vizinhos, etc. Estas redes, a priori, desmontam as relações sociais no lugar onde o migrante vivia, mas também se caracterizam pela sua reconstituição no lugar de destino, como foi possível observar em Rio das Pedras.

A descrição do processo de partida feita pelos moradores de Rio das Pedras é pronunciada, às vezes, com uma voz embargada; ao mesmo tempo o olhar é fixado no horizonte. Ocorrem algumas pausas, denotando a dificuldade em se resgatar, por meio da memória, a sua história. No caso de algumas mulheres, os olhos lacrimejaram e duas delas choraram, sem conseguirem conter a emoção causada pela lembrança da partida.

As experiências vividas por esse grupo se traduzem na antítese das propostas da racionalidade dos planejadores, via órgãos e instituições estatais, portadores de discursos de que ao planejamento regional caberia a redução das desigualdades regionais. 
Talvez o exemplo mais emblemático do fracasso dessa racionalidade sejam os projetos desenvolvidos no âmbito da SUDENE (Superintendência de Desenvolvimento do Nordeste), que apresentaram um caráter de complementaridade, sendo sua expressão principal a intensificação da concentração de capital em outra região - no caso, o Sudeste, mas que também beneficiou o capital privado nacional e estrangeiro. O tempo de sua existência (sua criação data de 1959), por si só, denuncia o fracasso de suas proposições. Na pauta desses agentes não se discutem as consequiências negativas de um planejamento influenciado por uma certa modernidade conservadora. Em síntese, parece haver um profundo distanciamento: do choro e das lamentações das mulheres de Rio das Pedras; do olhar triste e fixo no horizonte do Senhor Valdemar, que desde que chegou ao Rio de Janeiro em 1959, tem inventado e reinventado estratégias para sobreviver; das árduas condições de vida dos "Damiãos", que conviviam diariamente com a fome nos sertões pernambucano e paraibano; das "Marias Lúcias" que tiveram de abandonar a terra natal e as suas relações sociais ali vividas para acompanhar o seu marido, porque "lá não tinha emprego para a profissão dele". É fato que tantas outras situações semelhantes estão presentes nas vozes dos moradores de Rio das Pedras e certamente podem se repetir na fala dos outros indivíduos que viveram o mesmo drama e que não foram ouvidos. Aqueles órgãos não concebem um espaço verdadeiramente humano, como já reivindicado pelo professor Milton Santos. Os "dramas" (referidos por Lacoste, apud Chatelet, s/d) pessoais (ou sociais) são ignorados solenemente em favor de uma racionalidade, cujos resultados negativos são experimentados por aqueles que, ao migrarem, têm de lançar mão de estratégias para se reterritorializar para compensar o "território perdido".

\section{AS ESTRATÉGIAS DE RETERRITORIALIZAÇÃO DOS MIGRANTES NORDESTINOS EM RIO DAS PEDRAS}

Nas observações de campo, assim como nos depoimentos sobre o processo de chegada à metrópole do Grande Rio, são atestados os elementos que atravessam o processo de reterritorialização. Podem estar presentes nas estratégias de apropriação do território, assim como nos recursos mobilizados para dar-lhe sentido, dentre os quais se destaca a identidade regional, ela própria podendo responder pela expansão territorial. Nas entrevistas, foi solicitado aos migrantes que: descrevessem como foi a chegada ao Rio de Janeiro; expusessem como é viver em Rio das Pedras e os tipos de dificuldades que tiveram; fizessem uma comparação entre a vida no local de origem e no de destino.

A chegada significa, como não poderia deixar de ser, novas experiências com o espaço e o começo de novas relações sociais com esse espaço-outro. Chegar, pela primeira vez, em um grande centro urbano é, como diz Durham (1984:183) "encontrar uma situação completamente diferente, ante a qual os padrões de comportamento e seu equipamento cultural se revelam inadequados". Segue-se que um ajustamento inicial é acionado para a "reconstituição de seu universo". Alguns dos exemplos aparecem nas falas dos migrantes, quando relatam a sensação de estranhamento quando do desembarque na metrópole. Discorrem sobre as estratégias utilizadas para não se perderem ("olhava para o prédio mais alto", como disse uma das entrevistadas); comentam as diferenças entre o trabalho na roça e o que desenvolvem na cidade; as diferenças na alimentação, no caso das mulheres trabalhadoras domésticas; salientam que, com o tempo, acostumam-se, sugerindo dessa forma que se adaptaram ou absorveram os equipamentos culturais impostos no local de destino.

No tocante à reconstituição de novas relações sociais, no caso das mulheres solteiras, se deslocam para a relação na qual a posição da "patroa" tende a substituir a do pai. Não se trata mais de um padrão doméstico tradicional, em que o pai representava a figura central, regulando toda a organização familiar no local de origem. As atividades ou tarefas também se tornam estranhas ao que se fazia antes. Já com relação às mulheres casadas, a vida conjugal direciona a substituição da figura do pai pela do marido, embora se deva ressalvar que atualmente transformações culturais (mas não exclusivamente), tendem a modificar a estrutura familiar, o que pode ser exemplificado com o desmanche de uniões conjugais estáveis.

As constantes lamentações referentes à partida e à chegada reforçam a desterritorialização, na qual o território, no seu sentido simbólico, sobrepõese ao sentido material. As comprovações dessa situação também se mostraram repetidamente na voz dos migrantes, ao sinalizarem, como ocorreu em alguns casos nas entrevistas, em que ao chegar ao Rio de Janeiro, sentiram-se deslocados e, por isso, com o desejo de voltar de imediato, porque "Não conhecia nada aqui", ou como disse uma outra migrante "Era tudo esquisito, diferente!", ou como assinalado por outro, "Terra estranha! Terra estranha!".

Em geral, esse estranhamento também aparece associado com a situação de insegurança, sentida pelas dificuldades dos primeiros contatos com o "espaço-outro", representada pela 
ausência de conhecidos, por não disporem de um lugar para morar e ainda, na falta de uma ocupação laboral.

Esses fragmentos de entrevistas parecem demonstrar, simultaneamente, os processos de desterritorialização e o de reterritorialização. O primeiro pode ser indicado quando o entrevistado vê o local de chegada como "esquisito", ou diz que, no início, "tinha vontade de voltar", porque "você está em terra estranha" ou que no lugar onde vivia antes, embora as condições de vida fossem difíceis, se "tinha liberdade", os entes queridos estavam próximos, onde "você está à vontade" e por isso "você podia ser você mesmo". O segundo se dá quando o tempo passa, e então, o migrante adquire conhecimentos, inicia-se o processo de migração de parentes, estabelecem-se outras relações sociais de vizinhança ou recupera-se as que estavam no local de origem com a migração dos entes queridos mais próximos (irmãos, tios, cunhados, etc.), no trabalho, com conhecidos e com isso a reterritorialização, pois ampliam-se as redes de relações sociais, aumentam-se as possibilidades de ampliação dos horizontes referentes à aquisição de "capital social", entendido como maior margem de manobra para conseguir ocupações e desenvolver outras atividades, entre elas as de lazer, representado pelos encontros com conterrâneos ou mesmo na simples convivência diária. Depois, como disseram os entrevistados, "a gente se acostuma".

O arranjo de uma colocação no mercado de trabalho e a conquista de um lugar para morar, sem que se necessite pagar aluguel, constituem etapas para o processo de reterritorilização. Estas duas conquistas - a moradia e o emprego - são representativas do sucesso do deslocamento, ou seja, quando aquelas são alcançadas, as dificuldades referentes à vida na metrópole parecem estar superadas e a maioria dos migrantes entrevistados já não manifesta o desejo de retornar ao local de origem. Isto também explica, em grande parte, porque as "invasões" aos terrenos vizinhos e às construções dos condomínios de luxo ${ }^{1}$ (na metade dos anos 1980) próximos de Rio das Pedras são relatos enfáticos, incorporados à história coletiva dos moradores da comunidade.

Os moradores das localidades de Areal I e II e do Pantanal discorreram como seu deu o processo de ocupação dos terrenos onde estas áreas estão situadas. O início se deu com a ocupação dos referidos condomínios, envolvendo confrontos com renomadas empreiteiras, o poder público municipal e a polícia militar. Outra área contígua à Rio das Pedras, conhecida localmente por Pinheiros (situada no sopé da encosta da Floresta da Tijuca) tivera processos semelhantes, ou seja, também envolveu conflito. Essa ações culminaram na incorporação de estoques de terra ao núcleo original - o "miolo" da favela - à comunidade e viabializou a sua expansão territorial e incremento populacional.

O que se deseja destacar, neste caso é a manifestação de algumas das etapas de apropriação do território por uma parte significativa dos moradores de Rio das Pedras, sobretudo os que estiveram à frente de suas franjas de expansão. São várias etapas que incluem desde uma certa vigilância, a autoconstrução da habitação, até a medição, esta feita pela AMARP Associação de Moradores de Rio das Pedras. Essa última etapa consolida, internamente, o direito de posse do território e, finalmente, a dotação de infraestrutura: obras de saneamento básico e abastecimento de água; calçamento; canalização, a maioria das vezes, realizadas pelo próprio morador.

Durante as incursões na comunidade pôde-se perceber, sobretudo no
Pantanal, uma grande quantidade de aterros. Alguns de seus moradores, com carrinhos de mão, levavam entulhos para dentro de casa. Foi observado que alguns desses residentes, a partir de mutirão, preparavam canaletas de abastecimento de água e esgotamento sanitário. Em qualquer das vielas, naquela localidade, seus moradores deparavam-se, permanentemente, com a ameaça do rebaixamento do solo.

Entretanto, os entrevistados que residem nessa localidade apresentaram grande contentamento, pois demonstraram satisfação em mostrar suas casas. Ter o lugar onde morar adquire um caráter simbólico, representado, sobretudo, pelo sentimento de pertencimento à moradia. Diz um dos entrevistados, morador do Pantanal:

“(...) quando eu cheguei aqui não tinha nada para passar nesse pedacinho de rua, tinha que ir beirando aquele pedacinho de rua, tinha que ir beirando aquele barraco ainda, ia por cima de uma madeira para chegar até aqui, fui o primeiro a construir aqui... [disseram para ele:] Se você tiver coragem de fazer isso, pode fazer... (...) ali na lama... foram três semanas, saí dali e falei para o meu amigo: '- Daqui, eu vou sair pro meu barraco, tenho fé em Deus'. (...) fui aterrando, ajuntando, ajuntando e, agora estou com doze metros [de largura] por quatro de frente. [dentro de casa, apontando para o chão da cozinha:] o outro aterro aqui afunda, então, nem piso lá no fundo, ele está estourando, estourando todinho, mas... graças a Deus, chove bastante, a gente ouve na televisão, no rádio, pessoas morrendo soterradas, mas aqui, sinceramente, é uma tranqüilidade..." (Antônio, Ilhéus - BA).

Apesar de todos os problemas - 
rebaixamento do solo, inundações freqüentes, existência de ratos, cobras, etc., especificamente no Pantanal - e além do trabalho despendido nos finais de semana para a conservação das residências, não há espaço para desânimo referente às constantes cheias da Lagoa, localizada próxima ao Pantanal. Pelo contrário, quando relatavam a conquista do terreno, ou mesmo, quando conseguiram juntar recursos para a compra de seus "barracos", demonstravam-se orgulhosos. Alguns, todavia, manifestaram o desejo de morar nas proximidades da "pista" para estarem mais próximos das vias de transporte e por ter "menos lama, quando chove".

A regulação, ou para ser mais preciso, o ordenamento territorial é programado pela Associação e isto reforça o seu papel e sua legitimidade, através da medição e distribuição dos terrenos. Por sua vez, essas ações, articuladas às suas iniciativas assistencialistas, culminam no sentimento de pertencimento ao lugar, reforçando a sua territorialidade. "Ter" um lugar para morar corresponde a fazer parte de uma organização; ter direitos a uma propriedade aparece, agora, associado ao Ser.

Freqüentemente, os relatos do significado de "viver em Rio das Pedras" são associados às ações da Associação. Reforça-se aqui o seu "poder simbólico", nem sempre tão invisível, pois não pode prescindir de uma base material para dar suporte ao seu "poder consentido". Portanto, as diretrizes inerentes ao poder público são desempenhadas pela representação associativa.

Pode-se notar, nos discursos dos migrantes que descrevem os impacto quanto à mudança de lugar, os seguintes aspectos: o estranhamento da chegada; a saudade dos que ficaram; a depressão sentida na chegada que só parecem superadas quando as rela- ções sociais da origem são restabelecidas no local de destino. Isto sugere que a junção do lugar da reprodução com o "lugar" da produção consiste numa das etapas da reterritorialização. O "lugar" da reprodução traduz-se na conquista da moradia e das relações sociais - inclusive com uma instância em que os moradores delegaram poder, em decorrência da ausência do poder público. Já o "lugar da produção" pode ser observado na conquista de ocupações estáveis. É como se a partir da conquista de ambas (a moradia e um emprego estável) esse grupo social pudesse se livrar das condições de clandestinidade no seu próprio país.

O "lugar da produção" - do trabalho - se opõe, strictu sensu, ao "lugar da reprodução" por ser o lugar do "nãotrabalho", o "lugar da festa" (Martins, 1986:55). A separação destes dois lugares ocorre, de início, porque o migrante realiza a migração sozinho. Logo após, estabelece-se uma rede de relações sociais que acontece de várias maneiras: quando ocorre o retorno de férias de um desses migrantes, ao chegar, trazendo informações do lugar onde estava, provoca a migração de outros; quando o migrante, a partir desse retorno, casa-se, influencia a migração de parentes; ou ainda, quando o filho mais velho parte e depois agencia a migração dos demais irmãos. Durante as entrevistas foi recorrente a menção dos migrantes, em relação a esse processo, como por exemplo, o comentário do senhor Valdemar: "fui trazendo de um em um; estão todos aqui", ou, no caso de Dona Maria Elza, trazida pela irmã, "eu já tinha uma irmã morando aqui. Consegui falar com ela e ela mandou o dinheiro e eu vim". Disse ainda sua irmã, Raimunda: "Desde quando veio o primeiro, já é, como se diz, se localizou aqui e aí foi vindo, sempre um trazendo o outro e esse trazendo outro. Hoje em dia, a família está praticamente toda aqui; só estão lá os mais idosos, mas os mais jovens já estão todos aqui”.

Em todas as quarenta e duas entrevistas, situações similares se repetiram e, em quase todas, os migrantes e seus parentes residiam perto uns dos outros, ou mesmo em outras localidades da comunidade. Em uma das vielas, onde se entrevistou um baiano, de Ilhéus, todos os moradores eram parentes, como ele próprio informou: "A minha chegada aqui foi ótima! (...) nesse trecho de cá [apontando para algumas casas], ali, tudo é parente; ainda tem outras que moram com nós, que é parente dela [esposa]".

A partir da ativação das redes de relações sociais, Rio das Pedras foi se tornando uma "comunidade de nordestinos", como os seus representantes e moradores comentam e como divulgado nos meios de comunicação. Rio das Pedras constitui a síntese das estratégias desses grupos sociais que juntaram, ou no limite, aproximaram o "lugar da produção", do trabalho, com o "lugar da reprodução", "da festa", cuja manifestação pode ser percebida pela recriação, nessa comunidade, de uma "atmosfera nordestinizada", mesmo que o resgate da identidade regional opere por seletividade e permaneça cercado por ambigüidades.

\section{A SELETIVIDADE $\mathbf{E}$ AS AMBIGÜIDADES SOBRE O RESGATE DA IDENTIDADE REGIONAL}

O ponto de partida escolhido para analisar a identidade territorial nordestina, em Rio das pedras foi, então, a identificação desse espaço como o "lugar da festa”, sob a pressuposição de que ela é ativada, fundamentalmente, mas não exclusivamente, nas horas de 
lazer, na convivência, momento por excelência em que a sociabilidade ocorre com maior vigor.

Para Fernández (1998, não paginado), "tanto a cidade como a festa são fenômenos primordiais da civilização porque ambas exercem a função de promover altos níveis de sociabilidade". No caso das migrações, a festa possui uma propriędade singular que permite ao migrante, atesta Magnani (2003:256) "um ordenamento de todo seu estoque simbólico", porque possibilita, "na grande cidade, reconstruir uma nova identidade, reconstruir laços de parentesco e vizinhança, acostumar-se aos equipamentos urbanos". Promove, igualmente, "a junção do velho e do novo", em que "algumas coisas permanecem, muitas se transformam, outras ainda desaparecem".

Em Rio das Pedras, das vitrolas das casas dos seus moradores ouviam-se músicas, entre elas, as músicas sertanejas, mas o peso maior era o do forró. Grupos tradicionais e outros nem tanto, como "Falamansa", "Rastapé", "Forrosacana", entre outros, eram executados.

Não foi possível identificar, ainda segundo observações dos trabalhos de campo, setores, na comunidade, em que predominassem certos grupos de migrantes de determinado estado da Região; confirmava-se a unidade defendida enfaticamente pelas lideranças comunitárias: "tá tudo misturado", ou "é tudo uma comunidade só. O Rio das Pedras só foi dividido no nome", como enfatiza o vice-presidente da associação, que destaca um caráter de unidade que envolve tanto nordestinos quanto cariocas, embora venha sugerir, ainda que implicitamente, a hegemonia nordestina.

Entretanto, uma parte dos entrevistados, ao responderem questões relativas ao tempo de lazer, sobre o que faziam nos momentos de folga ou se, nestes momentos havia confraterniza- ção ou realização de encontros com parentes, as respostas eram a falta de tempo e, quando tinham folga, apresentavam cansaço, ou "falta de dinheiro", o que dificultava o deslocamento para os lugares onde poderiam acontecer as "festas". Todavia, alguns dos entrevistados do sexo masculino, com mais idade, disseram que, quando jovens, bebiam e freqüentavam a Feira de São Cristóvão, mas que, atualmente, não costumam realizar essas atividades. Uma das mulheres entrevistadas comentou que freqüentava a mesma feira, os forrós de Ipanema e do Asa Branca (na Lapa) além de participar, no Largo do Machado, de encontros semanais de nordestinos, onde até há bem pouco tempo se reuniam.

Houve também situações em que os moradores de Rio das Pedras disseram não freqüentar espaços de convivência, nem mesmo visitar parentes. Estes casos parecem indicar que as redes sociais desse grupo foram desativadas quando do início do processo migratório e, em seguida, após o seu estabelecimento na metrópole, não houve como reativá-las. Supõe-se que suas dificuldades induzem sua fragilidade, sobretudo, no que concerne à reterritorialização. De certo modo, isto é uma conseqüência dos baixos salários, do desemprego e mesmo da deterioração da relação capital/trabalho, o que pode reforçar a dificuldade de mobilizar recursos para realizar as festas, os encontros, ou para fortalecer mobilizações que levem à criação de centros de tradições ${ }^{2}$ ou algo congênere. Parece que este contexto tende a deslocar experiências desse grupo social em direção a uma atomização, em que o individualismo parece prevalecer.

Esta parece ser, então, uma das ambigüidades em que se manifesta o processo de reterritorialização em Rio das Pedras, sobretudo, quando se tem por alvo o resgate da identidade regio- nal como uma de suas estratégias, cujas dificuldades podem ser: de mobilizar recursos para a realização de festas para estar junto de seus pares; o desencantamento demonstrado em algumas das entrevistas, quando alguns dos entrevistados disseram que vir para o Rio de Janeiro "foi uma ilusão", ou "até agora não consegui nada". Esses casos parecem ser os de indivíduos que, ao migrar, não conseguiram se inserir em novas redes de relações. Estão desempregados e pagam aluguel, o que, por sua vez, confirma que ter uma ocupação estável e a moradia consistem em etapas importantes do processo de reterritorialização.

Se considerarmos a região Nordeste como um espaço de representação, aquele que é concebido pelos técnicos de planejamento, ou mesmo de uma representação dos grupos dominantes - as oligarquias locais - aos quais se somam os intelectuais, como Gilberto Freyre, Rachel de Queiroz, Ariano Suassuna, entre outros, arrisca-se a hipótese de que a referida região é uma invenção e nesse processo de invenção, não se considerou os espaços de representação, aqueles que se vinculam ao espaço vivido, carregado de simbolismo, saturado de significações ${ }^{3}$.

A identidade regional não mais se constrói sob a influência da nostalgia freyreana, nem mesmo sob a pena dos Romancistas de Trinta e nem se vincula à imagem que associava o nordestino ao sujeito que diante das penosas condições de vida no local de origem, oscilava entre o "trabuco e o rosário", isto é, apelava para o cangaço ou para o messianismo, como foi comentado por Djacir Menezes em sua clássica obra $O$ Outro Nordeste. O Sertão e sua natureza semi-árida (origem de quase todos os entrevistados) conforme os depoimentos dos moradores de Rio das Pedras, não consiste mais no repositório que os vincula à 
identidade regional porque quase não há menção às prolongadas estiagens, nem mesmo como causa principal do processo migratório. Não há também uma auto-atribuição "como sertanejos" pelos entrevistados, pois um ou outro diz que veio do "sertão brabo da Paraíba", não se referindo à seca (de que se criou toda uma matriz imagéticodiscursiva sobre o Nordeste), mas às árduas condições de vida. Portanto, as representações sociais sobre si mesmos não têm como base a natureza semi-árida do sertão.

O processo de reterritorialização dos migrantes nordestinos em Rio das Pedras demonstra a contradição entre o "espaço vivido" e o "espaço concebido". A forma como os romancistas, os técnicos de planejamento ou as elites regionais - neste caso o regionalismo, defendido por Freyre - concebiam o espaço regional parece não coincidir com a perspectiva das classes menos privilegiadas e, provavelmente, nem no local de origem, no passado, nem atualmente, no local de destino. Aquelas concepções não subsistem nem mesmo sob um caráter residual. É bem provável que jamais tenham coincidido

Houve também algumas situações em que os migrantes se sentiram hostilizados por conterrâneos que já estavam estabelecidos na metrópole há mais tempo, embora tais situações não tenham tido uma grande recorrência nas entrevistas.

As diferenças, neste caso, afluem em direção à relação entre "estabelecidos e outsiders" (Elias, 2000), na qual determinado grupo, por possuir maior tempo residindo num lugar, detém maiores privilégios, isto é, o tempo de residência marca a sua distinção como, por exemplo, ter maior tempo vivendo em Rio das Pedras garante maior capacidade de influenciar nas decisões da Associação. Alguns indivíduos afirmaram já ter ocupado pos- tos na sua diretoria. As lideranças comunitárias e os moradores que orbitam em torno da representatividade associativa em Rio das Pedras caracterizam-se por serem moradores mais antigos. Em entrevista realizada com o vice-presidente da Associação, este foi enfático quando o assunto dizia respeito à relação moradores recentes $\mathrm{X}$ moradores antigos, na qual dizia, "todos aderem", como se estivesse fazendo uma articulação entre a legitimidade alcançada pela AMARP e os interesses dos moradores mais antigos, os estabelecidos.

Situação semelhante parece se repetir, sobretudo quando se desloca para o que se poderia chamar de "conflitos de gerações". A segunda geração dos moradores de Rio das Pedras, os filhos de nordestinos, apresenta relativa recusa na valorização da origem dos seus pais. Mesmo que apenas um dos entrevistados tivesse comentado a respeito, uma das lideranças comunitárias disse ser comum filhos de nordestinos, nascidos no Rio de Janeiro, apresentarem, não explicitamente, rejeição à naturalidade dos pais.

A cultura popular ou a erudita regional e o que elas tinham de mais tradicional parecem ser, em alguns momentos, pouco ativadas - ou se admite pouca força por parte destas - para dar sentido à identidade regional. Em algumas das entrevistas pode-se notar pouco apego às tradições, como por exemplo, quando se perguntava aos moradores de Rio das Pedras, quais comidas típicas costumavam consumir. Alguns dos comentários dos migrantes soavam negativamente como, por exemplo, um dos entrevistados ao dizer que, depois de dezoito anos que partira do Nordeste, ao retornar e ao consumir os alimentos típicos do lugar onde nascera sentira-se mal.

Em outra entrevista um dos moradores afirma que ao passar na feira, que ocorre aos domingos e que ao ver os repentistas - cantadores de literatura de cordel que narram sagas de supostos heróis regionais, acompanhados por violas - não manifesta interesse.

A relação dos moradores de Rio das Pedras com a mobilização da sua identidade regional leva a duas interpretações. De um lado, há situações em que a identidade regional é fracamente mobilizada, o que pode estar associado à dificuldade de mobilizar recursos e, diante disto, parece não apresentar condições de aproximar o "lugar do trabalho", "da produção" com o "lugar do não-trabalho", da reprodução; um fraco apego às tradições, representado pela não valorização das origens de seus pais por parte dos filhos dos migrantes; a rejeição, em alguns casos, pelo que é tipicamente regional, como visto na relação entre os migrantes e os alimentos da região; o preconceito dos estabelecidos contra os de migração recente e, por fim, uma certa dificuldade em se falar do passado, como já aludido anteriormente, tudo dificulta o resgate das tradições do lugar de origem.

A recorrência à memória, capaz de unir espaço e tempo e que poderia fortalecer a identidade regional, neste caso tende ao enfraquecimento, dificultando a mobilização da identidade regional, o que foi visto durante as conversas com os moradores migrantes.

Pode-se, assim, diagnosticar os problemas que cerceiam o resgate da identidade regional em Rio das Pedras: ora existe pouca coesão entre as gerações; ora fraco recurso despendido à memória. Em ambas as situações estão presentes as dificuldades para ativar, plenamente, a identidade regional. $\mathrm{Na}$ comunidade, ela opera por seletividade, dependendo do contexto.

Em contraposição, há situações em que a identidade regional é vivida em toda a sua plenitude, sobretudo nas situações em que se pode ver a junção 
ou a aproximação do "lugar da produção" com o "lugar do não-trabalho"; quando Rio das Pedras se torna o "lugar da festa", em que se pode observar as conversas, nos finais de semanas, nas calçadas e nos bares; a musicalidade - sobretudo o forró - que soa nas casas, onde se cria toda uma atmosfera que "lembra" e que faz com que, na comunidade, se sinta "um pedacinho do Norte", como mencionado por uma das moradoras da comunidade; quando se observa a satisfação dos moradores das áreas mais problemáticas devido à precariedade das condições ambientais e sua luta para superá$\mathrm{las}^{4}$.

Há, entretanto, alguns fatores que explicam a fraca mobilização da identidade regional. Trata-se das mudanças culturais e que envolvem transformações na forma de apreensão das tradições e na forma de sua difusão que, possivelmente, podem afetar as visões de mundo tanto no local de destino quanto no de origem do grupo social em questão. Desses efeitos, em especial a "co-habitação" entre o próximo e o distante, está relacionada ao desenvolvimento das técnicas, percebido sobretudo na ampliação da arena em que ocorre este processo. $\mathrm{O}$ aumento do consumo, principalmente o que está ligado aos meios de comunicação de massa, contribui para aumentar a velocidade com que as informações são transmitidas. Deve-se subentender, contudo, que o "consumo é o conjunto de processos socioculturais em que se realizam a apropriação e os usos dos produtos" (Canclini, 1996:53). Este autor acrescenta que:

\footnotetext{
“(...) o anárquico crescimento urbano segue junto com a expansão dos meios eletrônicos. A industrialização e as migrações, que levaram à cidade nos últimos cinqüenta anos ... [milhões de habitantes] são parte da mesma política de modernização que
}

concentra o desenvolvimento cultural na expansão dos meios de comunicação de massa. $O$ desequilíbrio gerado pela urbanização irracional e especulativa é "compensado" pela eficácia comunicativa das redes tecnológicas" (p.79).

Segundo Ortiz (1998:108), "há um universo habitado por objetos compartilhados em grande escala" e, assim, o presente, o simultâneo, tende a se sobrepor ao passado, modificando ou dificultando o resgate das tradições, porque, se o que é pretérito prescinde da memória coletiva, seu maior inimigo, como assinala ainda este autor, é o esquecimento e é este que "espreita a evocação do passado, trabalhando no sentido de sua desagregação" (idem, p. 137). Torna-se necessário lutar contra o esquecimento, através da rememoração, para que não se fragilize a solidariedade entre as pessoas e, neste sentido, "comunidade e memória se entrelaçam".

\section{NOVOS PERCURSOS PARA OS MIGRANTES DE RIO DAS PEDRAS}

O esforço empreendido no desenvolvimento da pesquisa sobre os migrantes nordestinos em Rio das Pedras não conduziu para respostas acabadas. Ao contrário, tanto a desterritorialização quanto a reterritorialização são processos e como tais, sempre incompletos. O mesmo pode ser dito quanto aos processos identitários. Por essa razão, o vivido, multifacetado, saturado de (re) significações, impede que tenhamos juízos de valores ou imagens idealizadas e préconcebidas.

O processo de reterritorialização, especificamente, emerge ancorado em contextos mais amplos, portanto, complexos, destacando-se a mobilização seletiva da identidade territorial.

Em Rio das Pedras, como se pôde notar, a preocupação empreendida pelos diversos agentes que interagem com a comunidade tem se voltado mais para marcar a sua distinção no espaço metropolitano do que, propriamente, de resgatar a identidade regional, embora esta seja mobilizada seletivamente para dar sentido à territorialidade riopedrense. Esta é uma das razões que explica o porquê de se poder afirmar que um novo processo está em curso: não há um abandono de todo das tradições, dos costumes, mas também não uma incorporação total (se é que isso é possível) da identidade do local de destino.

\section{* Luciano Ximenes Aragão é Mestre em Geografia pela Universidade Federal Fluminense.}

\section{NOTAS}

1 - Trata-se de condomínios situados em terrenos contíguos a Rio das Pedras pertencentes ao Grupo Delfim, que, segundo entrevistas, estavam penhorados à Caixa Econômica Federal.

2 - Em 2003, o prefeito César Maia inaugurou o Centro de Tradições Nordestinas Luiz Gonzaga, no antigo Pavilhão de São Cristóvão, nas proximidades do lugar onde ocorria a tradicional "Feira dos Paraíbas". Este então, tornou-se o único centro de tradições nordestinas no Rio de Janeiro. Constituiu-se numa iniciativa política que parece assumir contornos paternalistas ou populistas, além de disciplinadora do espaço, pois procura reunir num único local e com regras "institucionalizadas" um evento de cultura popular. A transferência, da rua para o pavilhão onde esse evento cultural se realiza não foi, desse modo, uma iniciativa popular; sugere-se, assim, que a racionalidade política sobrepõe-se à espontaneidade dos indivíduos.

3 - Para aprofundamento dos conceitos de espaços de representação, práticas sociais e de representações do espaço, ver Lefebvre, 1981.

4 - A manutenção de atributos que envolve a identidade regional é permeada por 
contradições; ela opera por seletividade, ainda que inconscientemente, ou seja, houve situações, por exemplo, em que um mesmo entrevistado vive intensamente "a atmosfera nordestinizada" de Rio das Pedras, admitindo seu "apego" à comunidade exatamente por essa razão. Porém sente-se pouco à vontade em falar sobre o local de origem, sobre os seus hábitos que estão relacionados com o lugar onde nasceu porque suas ligações com ele são muito reduzidas. De forma geral, isto induz que o migrante não perdeu de todo a sua identidade original, mas que também não incorporou uma identidade de destino. Parece, enfim, que um novo arranjo ou negociação identitária, em Rio das Pedras, está em curso.

\section{REFERÊNCIAS BIBLIOGRÁFICAS}

\section{BURGOS, Marcelo B.}

(2002) "Favela, cidade e cidadania em Rio das Pedras". In: BURGOS, Marcelo B. (org.) A utopia da Comunidade: Rio das pedras, uma favela carioca. Rio de Janeiro, Editora Loyola/PUC.

CANCLINI, N. G.

(1996) Consumidores e cidadãos. Rio de Janeiro, Editora da UFRJ.

DURHAN, E.

(1984) A caminho da cidade. São Paulo, Editora Perspectiva.

\section{ELIAS, Norbert}

(2000) Os estabelecidos e os outsiders. Rio de Janeiro, Jorge Zahar Editor.

FERNANDES, Nelson N.

(1998) La ciudad y la fiesta. Orígenes, desarrollo y siginificado de las "escolas de samba" de Río de Janeiro (1928-1941). Scripta Nova. Revista Eletrónica de Geografía e Ciencias Sociales. Barcelona, Universidad de Barcelona.

\section{LACOSTE, Y.}

(s/d) A Geografia. In: CHATELET, F. A filosofia das ciências sociais: de 1860 aos nossos dias. Vol. 7. Rio de Janeiro, Jorge Zahar Editor.
LEFEBVRE, $\mathrm{H}$.

(1981) La Production de

L'Espace. Paris, Fayard.

LEFEBVRE, $\mathrm{H}$.

(1976) Espacio y politica. Barcelona, Ediciones Península.

MAGNANI, J. G. C.

(2003) Festa no pedaço: Cultura popular e lazer na cidade.

São Paulo, Editora da UNESP

(Terceira Edição).

MARTINS, José de Souza
(1986) Não há terra para plantar neste verão. Petrópolis, Vozes.

MENEZES, Djacir

(1970) O outro Nordeste: Ensaio sobre a evolução social e política do Nordeste da "civilização do couro" e suas implicações históricas nos problemas gerais. Rio de Janeiro, Artenova Editora.

ORTIZ, Renato

(1998) Mundialização e cultura. São Paulo, Editora Brasiliense.

\section{FÓRUM \\ SOCIAL \\ MUNDIAL \\ DAS MIGRAÇÕES}

\section{Cidadania Universal e Direitos Humanos}

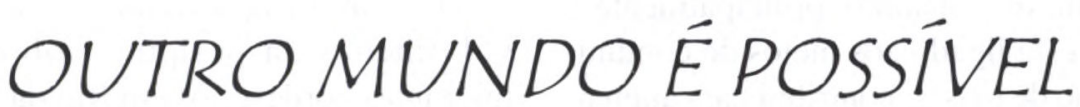

Rivas-Vaciamadrid, Madrid, Espanha 22 a 24 de junho de 2006

\section{www.fsmm2006.org}

\begin{tabular}{cccc} 
CEAR-Comisión Española & Grito dos \\
de Ayuda al Refugiado & Excluídos & $\begin{array}{c}\text { SPM - Serviço Pastoral } \\
\text { dos Migrantes }\end{array}$ & $\begin{array}{c}\text { Rivas } \\
\text { Vaciamadrid }\end{array}$ \\
\hline
\end{tabular}

